\title{
Use of urinary naloxone levels in a single provider practice: a case study
}

\author{
Jill S. Warrington ${ }^{1,2^{*}} \mathbb{0}$, Kaitlyn Booth ${ }^{1}$, Gregory S. Warrington ${ }^{3}$ and Samuel Francis-Fath ${ }^{1}$
}

\begin{abstract}
Background: Urine drug monitoring for medications for opioid use disorder (MOUD) such as buprenorphine can help to support treatment adherence. The practice of introducing unconsumed medication directly into urine (known as "spiking" samples) has been increasingly recognized as a potential means to simulate treatment adherence. In the laboratory, examination of the ratios of buprenorphine and its metabolite, norbuprenorphine, has been identified as a mechanism to identify "spiked" samples. Urine levels of naloxone may also be a novel marker in cases where the combination buprenorphine-naloxone product has been administered. This case study, which encompasses one provider's practice spanning two sites, represents a preliminary report on the utility of using urinary naloxone as an indicator of "spiked" urine toxicology samples. Though only a case study, this represents the largest published evaluation of patients' naloxone levels to date.

Case presentation: Over a 3-month period across two practice sites, we identified 1,223 patient samples with recorded naloxone levels, spanning a range of 0 to $12,161 \mathrm{ng} / \mathrm{ml}$. The average naloxone level was $633.65 \mathrm{ng} / \mathrm{ml}$ with the majority (54\%) of samples $<300 \mathrm{ng} / \mathrm{ml}$. $8.0 \%$ of samples demonstrated extreme values of naloxone (> $2000 \mathrm{ng} /$ $\mathrm{ml})$. One practice site, which had increased evidence of specimen tampering at collections, had a greater percent of extreme naloxone levels (> $2000 \mathrm{ng} / \mathrm{ml}$ ) at $9.3 \%$ and higher average naloxone level $(686.8 \mathrm{ng} / \mathrm{ml})$, in contrast to a second site $(570.9 \mathrm{ng} / \mathrm{ml} ; 6.4 \%$ at $>2000 \mathrm{ng} / \mathrm{ml})$ that did not have known reports of specimen tampering.

Conclusions: We postulate that naloxone may serve as an additional flag to identify patient "spiking" of urine samples with use of the combination product of buprenorphine-naloxone.
\end{abstract}

Keywords: Naloxone, Urine drug testing, Spiking, Buprenorphine

\section{Background}

Medications for opioid use disorder (MOUD) are critical tools for reducing opioid use, mitigating opioid withdrawal, enhancing treatment retention, as well as reducing the incidence of opioid-related overdoses, the acquisition of HIV and chronic hepatitis, and death among patients with opioid use disorder (OUD; [1, $2])$. Urine drug testing has been advocated as an effective strategy to evaluate treatment adherence to MOUD

\footnotetext{
*Correspondence: jwarrington@aspenti.com

${ }^{2}$ Robert Larner School of Medicine, Department of Pathology

and Laboratory Medicine, University of Vermont Medical Center, 111 Colchester Avenue, Burlington, VT 5401, USA

Full list of author information is available at the end of the article
}

drugs such as buprenorphine and methadone as well as to identify unexpected drug use in patients with substance use disorders [3].

Consideration for urine specimen tampering has been long advocated as an important part of urine drug testing [4]. Overall rates of urine specimen tampering in various urine drug testing settings, as determined by specimen validity testing, can range from approximately 1 to $3 \%$ of cases [5]. While urine specimen tampering is not an uncommon practice, there has been far less evaluation of how often patients "spike" urine with prescription medications, by inserting unconsumed drug directly into urine, to simulate treatment adherence [6]. Patients with OUD may be motivated to simulate treatment adherence

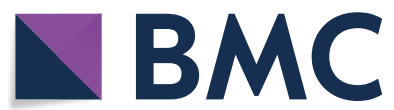

(c) The Author(s) 2020. This article is licensed under a Creative Commons Attribution 4.0 International License, which permits use, sharing, adaptation, distribution and reproduction in any medium or format, as long as you give appropriate credit to the original author(s) and the source, provide a link to the Creative Commons licence, and indicate if changes were made. The images or other third party material in this article are included in the article's Creative Commons licence, unless indicated otherwise in a credit line to the material. If material is not included in the article's Creative Commons licence and your intended use is not permitted by statutory regulation or exceeds the permitted use, you will need to obtain permission directly from the copyright holder. To view a copy of this licence, visit http://creativeco mmons.org/licenses/by/4.0/. The Creative Commons Public Domain Dedication waiver (http://creativecommons.org/publicdomain/ zero/1.0/) applies to the data made available in this article, unless otherwise stated in a credit line to the data. 
for a variety of reasons including fear of repercussions if they aren't adherent to medications, ability to divert/sell controlled substances, and/or desire to not disappoint their provider [7].

In the context of buprenorphine treatment, recent studies have identified the use of the ratio of buprenorphine and its metabolite, norbuprenorphine, to identify the practice of spiking buprenorphine products into a urine specimen $[6,8,9]$. Rates of unexpected norbuprenorphine:buprenorphine $(\mathrm{N}: \mathrm{B})$ ratios, as a marker of possible specimen adulteration with the prescribed medication, ranged from 0.6 to $27 \%$ of samples [10].

A limited number of reports have begun to examine the utility of naloxone as a marker of spiking the combination buprenorphine-naloxone product into urine specimens [11]. For example, Sobolesky et al. [12] identified the pattern of high buprenorphine, low norbuprenorphine and high naloxone in two patients, leading the authors to suspect these were "spiked" specimens to simulate treatment adherence.

While it is increasingly appreciated that naloxone levels are detectable in urine after sublingual administration of the combination buprenorphine-naloxone product [13], there is little characterization of what might constitute an elevated level of naloxone for the identification of potential specimen spiking with original drug into urine.

In this case study, we examined the naloxone levels in patients of one provider across two practice settings. Since one of the two sites had repeated anecdotal reports of specimen tampering at the point of urine collection, we were interested in whether differences in naloxone levels would be found across the two settings.

\section{Case presentation}

Urine samples were collected by observed collection from June to August 2018 across two practice sites. During this time, we identified 1223 patient samples, spanning 275 unique patients, with recorded naloxone levels. Naloxone levels ranged from 0 to $12,161 \mathrm{ng} / \mathrm{ml}$ with an average naloxone level of $633.65 \mathrm{ng} / \mathrm{ml}$ (1 s.d. 1039.38). The median naloxone level was $253 \mathrm{ng} / \mathrm{ml}$ with the first quartile at $57.5 \mathrm{ng} / \mathrm{ml}$ and the third quartile at $762 \mathrm{ng} / \mathrm{ml}$. $54 \%$ of samples were $<300 \mathrm{ng} / \mathrm{ml}$. $8.0 \%$ of samples demonstrated extreme values of naloxone $(>2000 \mathrm{ng} / \mathrm{ml})$.

Anecdotal reports from collectors performing observed collections suggested a relatively higher rate of attempts to tamper specimens at site 1 in contrast to site 2 , despite shared staffing and common provider practice protocols between the two sites. Among the witnessed events, collectors identified theft of empty cups and "dumpster diving" for disposed urine cups behind the provider office. In addition, a review of specimen validity testing (creatine, specific gravity, and general oxidants) performed at both sites demonstrated a higher incidence of abnormal specimen validities at site 1 (30 patient samples) in comparison to site 2 (18 patient samples).

An analysis of naloxone levels across the two sites was performed to assess if any differences were detectable in this marker. The average naloxone level for patients at Site 1 was $686.8 \mathrm{ng} / \mathrm{ml}$ over the 3-month period in comparison to $570.9 \mathrm{ng} / \mathrm{ml}$ at Site 2 (see Fig. 1; box and whisker plot; two-sample Student's T-Test $\mathrm{p}<0.05$ ). The proportion of extreme naloxone levels, defined as $>2000 \mathrm{ng} / \mathrm{ml}$, was higher at Site $1(9.3 \%)$ in contrast to Site 2 (6.4\%). Further investigation into the differences between these two sites demonstrated a difference across naloxone levels (Fig. 2).

For comparison, we also evaluated the $\mathrm{N}: \mathrm{B}$ ratios in the high naloxone cases $(>2000 \mathrm{ng} / \mathrm{ml})$ in comparison to those below $2000 \mathrm{ng} / \mathrm{ml}$. We found the mean $\mathrm{N}: \mathrm{B}$ ratio in the elevated naloxone levels was 2.6 in comparison to the mean N:B ratio of 3.9 in cases with naloxone levels below $2000 \mathrm{ng} / \mathrm{ml}$.

\section{Discussion and conclusions}

Naloxone is extensively metabolized by first-pass metabolism by glucuronidation, $\mathrm{N}$-dealklyation and reduction (Suboxone, package insert). Since naloxone demonstrates low bioavailability through oral or sublingual administration, significantly elevated levels of naloxone are not considered to be routinely identified in urine specimens [14]. A limited number of studies have begun to evaluate naloxone levels in urine $[13,14]$ and have demonstrated

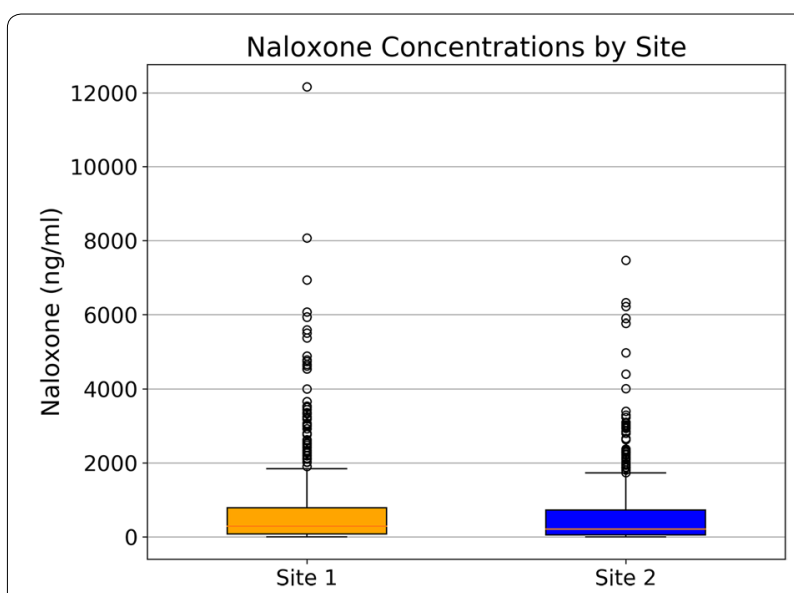

Fig. 1 Naloxone concentrations by Site: A box-and-whisker plot of the distribution of naloxone levels $(\mathrm{ng} / \mathrm{ml})$ at Sites 1 and 2 is presented. Each box depicts the 25 th and 75 th percentiles with the median depicted by an orange horizontal line. The whiskers extend above the 75 th percentile by 1.5 times the interquartile range for each site. Values outside of the whiskers are marked individually 


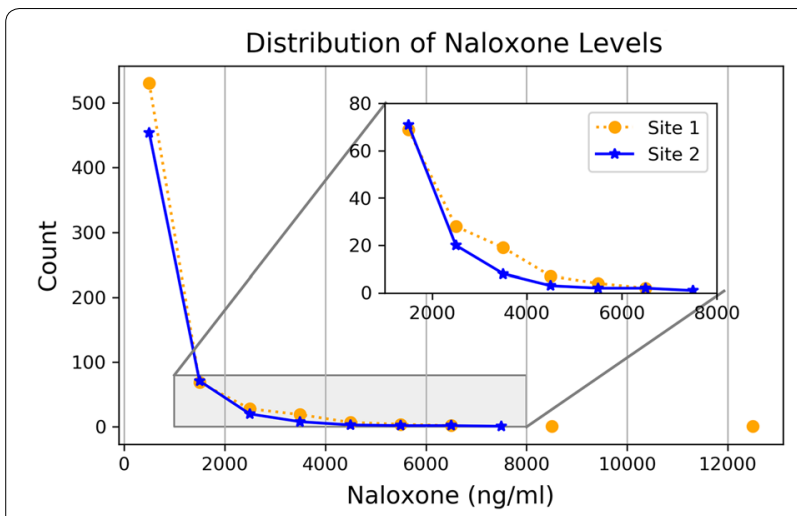

Fig. 2 Distribution of naloxone levels: a line histogram of naloxone concentrations $(\mathrm{ng} / \mathrm{ml})$ vs. the occurrence of values (count) is presented. Values are binned by $1000 \mathrm{~s}$. Site 1 (dotted, orange line) and Site 2 (solid, blue line) are compared. An inset focused on a narrower range of values

that detectable naloxone levels may present in urine after oral/sublingual administration. For example, in one study, naloxone ranged from 5 to $1700 \mathrm{ng} / \mathrm{ml}(\mathrm{n}=40$ patients, [11]).

In this study, naloxone ranged from 0 to $12,161 \mathrm{ng} / \mathrm{ml}$ $(\mathrm{n}=1223$ samples among 275 unique patients) with $8.0 \%$ of samples demonstrating extreme values of naloxone ( $>2000 \mathrm{ng} / \mathrm{ml}$ ). To our knowledge, this is the first study to report naloxone levels as high as $12,161 \mathrm{ng} / \mathrm{ml}$; this may be in part due to reporting limits in the upper range in many laboratories [13]. This study suggests, however, that examination of these upper ranges $(>1000 \mathrm{ng} / \mathrm{ml}$ ) may provide important insights into clinical care.

A wide range of naloxone levels are seen even at lower naloxone concentrations. This may be related to pharmacokinetic differences in how naloxone is absorbed, distributed, metabolized, and excreted [14]. Individual variability in genetics, nutrition, concurrent medications, and/or the presence of hepatic impairment are among the factors that may alter the urinary levels of naloxone [14].

In this study, we examined differences in naloxone concentrations across two practice settings that shared staffing, provider care, policies and protocol. The only known differences between the two practices were the location of the office and a reported higher rate of witnessed attempts to tamper at Site 1 in contrast to Site 2. The higher rate of tampering at Site 1 was further corroborated by the identification of a doubling of flagged specimen validity tests at Site 1 in comparison to Site 2 .

While the median values between the two sites were somewhat similar (Site 1: $290 \mathrm{ng} / \mathrm{ml}$; Site 2: $207 \mathrm{ng} / \mathrm{ml}$ ), we found a higher percentage of samples with extreme values of naloxone, as defined by greater than $2000 \mathrm{ng} /$ $\mathrm{ml}$ at the site of possible tampering (Site 1; 9.3\%) in contrast to the site with no significant report of tampering (Site 2; 6.4\%).

It was not surprising that the median naloxone values were similar between the two practices because the two provider locations were similar in nearly every respect: a single provider with shared staffing, policies and protocol and prescribing practices. The significant difference between the two sites was instead in the percent of specimens with naloxone values $>2000 \mathrm{ng} / \mathrm{ml}$, corroborating the clinical impression that tampering, and potentially the practice of spiking samples into urine to simulate treatment adherence, was more common in Site 1.

While differences were identified between Site 1 and Site 2 , we cannot definitively conclude these differences can be attributed to increased rates of "spiking" of urine specimens. There remain several mechanisms by which naloxone may exceed what are typically lower levels in urine, including recent Narcan administration, intravenous naloxone administration or pharmacokinetic alterations in gastrointestinal absorption, metabolism, or distribution [14, 15]. A more systematic evaluation correlating individual naloxone levels with associated buprenorphine levels will be necessary to more fully identify whether naloxone is a reasonable marker for the practice of spiking of urine specimens. However, the association to the clinically-identified observations of tampering attempts between the two sites is supportive of the potential use of naloxone in identifying treatment adherence.

Testing for naloxone in urine is a readily available option in the clinical laboratory. While additional examination is required, this study supports that naloxone may serve as a reasonable flag to identify potential spiking of buprenorphine-naloxone combination product into urine. This is further substantiated by the lower mean $\mathrm{N}: \mathrm{B}$ ratio in elevated $(>2000 \mathrm{ng} / \mathrm{ml})$ naloxone cases. This study, to our knowledge, represents the largest collection of cases with demonstrably high naloxone levels. Further, this report demonstrates cases with significantly higher than seen previously for naloxone.

\section{Abbreviations}

MOUD: medications for opioid use disorder; OUD: opioid use disorder; LC-MS/ MS: liquid chromatography-tandem mass spectrometry.

\section{Acknowledgements}

The authors wish the acknowledge Andrew Walsh for his technical assistance in supporting the manuscript. We also want to thank Christopher Powell, Chief Executive Officer, for his continued support of scholarship (Andrew Walsh is a scientist at Ammon Labs in Massachusetts). 


\section{Authors' contributions}

JSW, the corresponding author, gathered the relevant data from both the data science team, the collections team and the extended clinical team; coordinated with the Institutional Review Board at her home institution, the University of Vermont Medical Center; wrote the manuscript and prepared the document for submission. SFF was responsible for data collection and analysis He also contributed significantly to the preparation of the manuscript. GSW contributed significantly to the data analysis and prepared all figures for submission. All authors read and approved the final manuscript.

\section{Funding}

Research for third author is partially supported by Simons Foundation Collaboration Grant for Mathematicians 429570.

\section{Availability of data and materials}

The datasets generated and/or analyzed during the current study are not publicly available due to the need to support the privacy of patients and providers but are available in an aggregated, de-identified from the corresponding author on reasonable request.

\section{Ethics approval and consent to participate}

According to the policy defining activities which constitute research at the University of Vermont/University of Vermont Medical Center, this work met criteria for operational improvement activities exempt from ethics review.

\section{Consent for publication}

Not applicable.

\section{Competing interests}

Samuel Francis-Fath and Kaitlyn Booth are salaried by Aspenti Health, a laboratory focused on population health management for Substance Use Disorders. Jill S. Warrington carries a non-salaried position as Chief Medical Officer at Aspenti Health. She also is a member of the community advisory council at Blue Cross Blue Shield of Vermont.

\section{Author details}

${ }^{1}$ Aspenti Health, South Burlington, VT, USA. ${ }^{2}$ Robert Larner School of Medicine, Department of Pathology and Laboratory Medicine, University of Vermont Medical Center, 111 Colchester Avenue, Burlington, VT 5401, USA.

${ }^{3}$ Mathematics and Statistics, University of Vermont, Burlington, VT, USA.

Received: 15 July 2019 Accepted: 4 January 2020

Published online: 15 January 2020

\section{References}

1. Fullerton CA, Kim M, Thomas CP, Lyman DR, Montejano LB, Dougherty $\mathrm{RH}$, et al. Medication-assisted treatment with methadone: assessing the evidence. Psychiatr Serv. 2014;65:146-57.
2. Velander JR. Suboxone: rationale, science, misconceptions. Ochsner J. 2018;18:23-9.

3. Jarvis M, Williams J, Hurford M, Lindsay D, Lincoln P, Giles L, Luongo $P$, et al. Appropriate use of drug testing in clinical addiction medicine. J Addict Med. 2017;11:163-73.

4. Jaffee WB, Trucco E, Levy S, Weiss RD. Is this urine really negative? A systematic review of tampering methods in urine drug screening and testing. J Subst Abuse Treat. 2007;33:33-42.

5. Lin SY, Lee HH, Lee JF, Chen BH. Urine specimen validity test for drug abuse testing in workplace and court settings. J Food Drug Anal. 2018;26(1):380-4.

6. Accurso AJ, Lee JD, McNeely J. High prevalence of urine tampering in an office-based opioid treatment practice detected by evaluating the norbuprenorphine to buprenorphine ratio. J Subst Abuse Treat. 2017;83:62-7.

7. Yokell MA, Zaller ND, Green TC, Rich JD. Buprenorphine and buprenorphine/naloxone diversion misuse, and illicit use: an international review. Curr Drug Abuse Rev. 2011:4:28-41.

8. Suzuki J, Zinser J, Issa M, Rodriguez C. Quantitative testing of buprenorphine and norbuprenorphine to identify urine sample spiking during office-based opioid treatment. Subst Abuse. 2017;38:504-7.

9. Lee D, Bazydlo LAL, Goldberger BA. Spiking in a pain medicine clinic: an attempt to simulate adherence. Pain Med. 2015;16:1449-511.

10. Mcmillin GA, Davis R, Carlisle H, Clark C, Marin SJ, Moody DE. Patterns of free (unconjugated) buprenorphine, norbuprenorphine, and their glucuronides in urine using liquid chromatography-tandem mass spectrometry. J Anal Toxicol. 2012;36:81-7.

11. Heikman P, Häkkinen M, Gergov M, Ojanpera I. Urine naloxone concentration at different phases of buprenorphine maintenance treatment. Drug Test Anal. 2014;6:220-5.

12. Sobolesky PM, Smith BE, Pesce AJ. Fitzgerald RL interpretation of pain management testing results using case examples. JALM. 2018;2:610-21.

13. Strickland DM, Burson JK. Sublingual absorption of naloxone in a large clinical population. J Drug Metab Toxicol. 2018;9:2.

14. Stone, JA Pesce AJ, Fitzgerald RL. 2017 Fake news, alternative facts or just normal pharmacokinetics? High urine naloxone concentrations in patients prescribed sublingual buprenorphine-naloxone (BNX). MSACL EU Abstract.

15. Colucci SV, Perrino PJ, Shram M, Bartlett C, Wang Y, Harris SC. Abuse potential of intravenous oxycodone/naloxone solution in nondependent recreational drug users. Clin Drug Invest. 2014;34(6):421-9.

\section{Publisher's Note}

Springer Nature remains neutral with regard to jurisdictional claims in published maps and institutional affiliations.
Ready to submit your research? Choose BMC and benefit from:

- fast, convenient online submission

- thorough peer review by experienced researchers in your field

- rapid publication on acceptance

- support for research data, including large and complex data types

- gold Open Access which fosters wider collaboration and increased citations

- maximum visibility for your research: over 100M website views per year

At BMC, research is always in progress.

Learn more biomedcentral.com/submissions 